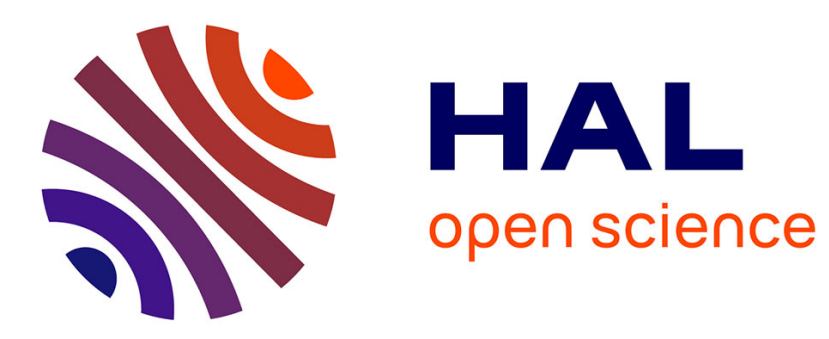

\title{
Teaching Energy Efficiency in Manufacturing Using Gamification: A Case Study
}

Mélanie Despeisse, Peter Lunt

\section{To cite this version:}

Mélanie Despeisse, Peter Lunt. Teaching Energy Efficiency in Manufacturing Using Gamification: A Case Study. IFIP International Conference on Advances in Production Management Systems (APMS), Sep 2017, Hamburg, Germany. pp.419-426, 10.1007/978-3-319-66926-7_48 . hal-01707249

HAL Id: hal-01707249

https://hal.inria.fr/hal-01707249

Submitted on 12 Feb 2018

HAL is a multi-disciplinary open access archive for the deposit and dissemination of scientific research documents, whether they are published or not. The documents may come from teaching and research institutions in France or abroad, or from public or private research centers.
L'archive ouverte pluridisciplinaire HAL, est destinée au dépôt et à la diffusion de documents scientifiques de niveau recherche, publiés ou non, émanant des établissements d'enseignement et de recherche français ou étrangers, des laboratoires publics ou privés.

\section{(c)(1)}

Distributed under a Creative Commons Attribution| 4.0 International License 


\title{
Teaching Energy Efficiency in Manufacturing Using Gamification: a case study
}

\author{
Mélanie Despeisse ${ }^{1}$ and Peter Lunt $^{2}$ \\ ${ }^{1}$ Industrial and Materials Science, Chalmers University of Technology, Sweden \\ Melanie.despeisse@chalmers.se \\ ${ }^{2}$ Manufacturing Engineering, Airbus Operations Ltd, Broughton, United Kingdom \\ peter.Iunteairbus.com
}

\begin{abstract}
Sustainability is a critical topic and needs to be systematically integrated in engineering education and professional training courses in manufacturing organisations. Eco-efficiency is a key sustainability concept but it can be challenging to teach as it is highly practical and thus ill-fitted for purely classroom environments. Games and simulations provide a good mechanism for effective and engaging teaching on such practical topics. This paper describes a case study of four game sessions ran in a manufacturing company. This empirical research shows how the card game 'One thousand $\mathrm{kWh}$ ' enabled participants to actively learn about energy efficiency in manufacturing operations, and to explore sustainable manufacturing practices and barriers to implementation.
\end{abstract}

Keywords: Eco-efficiency · Energy efficiency · Manufacturing · Games · Teaching and learning $\cdot$ Education

\section{Introduction}

Complex issues, such as globalization, industrial digitalization and sustainability, need to be more systematically integrated in engineering and management education. Broadening the set of learning experiences and teaching methods in engineering curricula is crucial to provide engineering students with the skills and knowledge required to respond to new industry needs [1]. Typical production engineering courses largely consist of lectures in which concepts and theories are conveyed. Short projects and practical exercises give students the opportunity to put this knowledge into practice and attain deeper learning by engaging more actively with the course material. Ideally, students should also carry out industry projects to experience the challenges and complex phenomena occurring in real-world manufacturing environments.

Focusing on sustainability, the skills required to address today's industry needs are envisioning, critical thinking and reflection, systemic thinking, collaboration and decision-making in uncertain and paradoxical conditions [2-5]. To address this challenge, a toolkit (Figure 1) was developed to engage students (in higher education) and trainees (in professional courses) to learn more actively about eco-efficiency and sustainable manufacturing [6]. The toolkit aims to simplify and gamify sustainability concepts. 


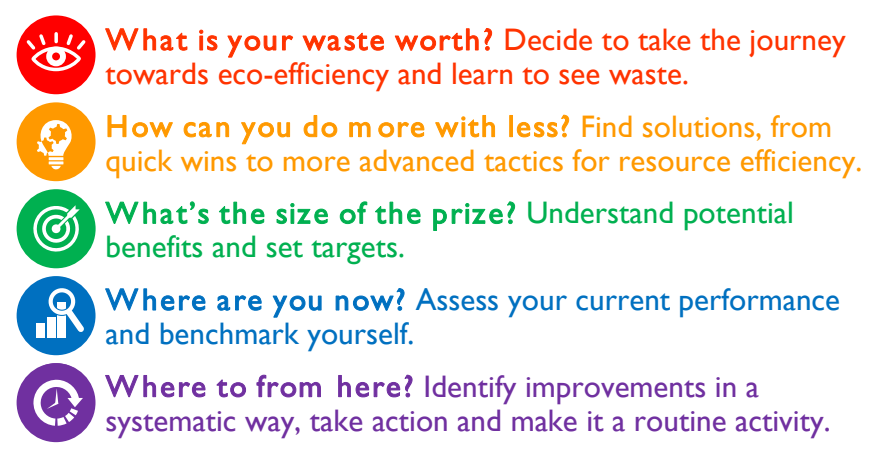

Fig. 1. The five elements of the eco-efficiency toolkit

This eco-efficiency toolkit is composed of five activities (or "elements"): (1) see waste, (2) find solutions, (3) set targets, (4) assess yourself, and (5) create good habits [6]. One notable tool in this eco-efficiency toolkit is the card game 'One thousand $\mathrm{kWh}$ '. It addresses various aspects of the toolkit with practical, industry-relevant learning outcomes. The game focuses in good practices for energy efficiency in manufacturing operations along with the typical barriers of implementation. In this paper, we describe how the game is designed, the mechanics of its game play, and the results of an experiment composed of four pilot sessions conducted with Airbus employees. Finally, we discuss the pros and cons of using games for education and provide some next steps for the sustainability games.

\section{Game Design and Development}

The card game was developed incrementally based on a trial-and-error approach. Three prototypes, each being iteratively improved based on player feedback, were produced and tested before the final product was professional printed and packaged. The rules are largely based on a French card game, Mille Bornes, developed in the 50s. It was selected for its simplicity and popularity which is proof that the format and concept work well for a broad audience.

The game is set to be easy to learn and playable within 30 minutes. Besides keeping the rules as simple and intuitive as possible, it is critical to provide sufficient context to make the learning experience as quick, effortless (and fun) as possible. This is important to address a typical drawback of using games as an educational tool: players can easily get carried away and forget about the learning experience.

The first two prototypes were tested multiple times in informal meetings with coworkers at the University of Cambridge during breaks and after work. This provided a more robust content for the third prototype which was then presented to industrial partners. The prototype format was good enough for the purpose but lacked the intuitive design to make the rules and mechanics quickly understood. The final product was largely improved by using bright colours, symbols and large fonts to clarify the cards categories and their relationship. A sample of the final card game is shown in Fig. 2. 


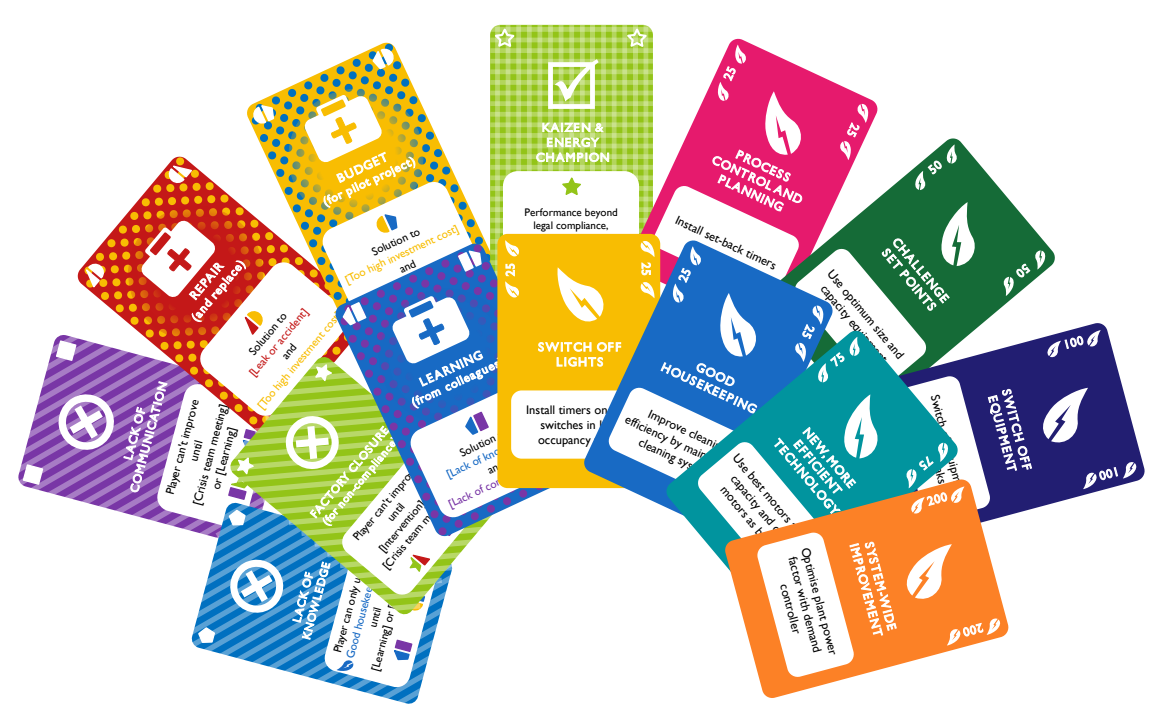

Fig. 2. Samples from the One thousand kWh card game

The card game consists of four categories of cards described in the next subsections.

1) Improvement cards (plain background). This category consists of a collection of sustainable manufacturing practices focused on energy efficiency. These practices were mainly sourced from the IAC database [7]. The practices selected were:

- the most recommended, capturing the most often overlooked practices;

- the most implemented, considered as the easiest practice to implement;

- the shortest payback time, representing the most economical practices;

- the largest savings, often associated with the most expensive practices as they require high capital investment in new equipment/machinery.

Due to the space constraint and the need for the improvements to be quickly read and understood while playing, some of the practices were rephrased or simplified based on formulation found in other sources [8-10]. This aspect was crucial as there is little time to reflect on the meaning of the practice in a game environment.

The practices were then sorted and grouped into seven types of improvement and associated with a generic value to reflect its average impact on energy savings:

1. Switch off lights $(25 \mathrm{kWh})$;

2. Good housekeeping ( $25 \mathrm{kWh})$;

3. Process controls and production planning $(25 \mathrm{kWh})$;

4. Challenge set points $(50 \mathrm{kWh})$;

5. New, more efficient technology $(75 \mathrm{kWh})$;

6. Switch off equipment (100 kWh);

7. System-wide improvement (200 kWh). 
2) Barrier cards (striped background). There are five types of barriers. Each barrier can be removed by two types of remedy [name in brackets], with improvement exceptions [italic name in brackets] for the first two barriers.

1. Too high investment cost: Player can still play [Switch off lights] improvements as they are relatively high budget, until [Budget] or [Repair] remedy is played;

2. Lack of knowledge: Player can still play [Good housekeeping] improvements as they are basic improvements that do not require advanced knowledge, until [Learning] or [Budget] remedy is played;

3. Lack of communication: Player cannot play any improvement until [Crisis team meeting] or [Learning] remedy is played;

4. Factory closure (for non-compliance): Player cannot play any improvement until [Intervention] or [Crisis team meeting] remedy is played;

5. Leak, accident or product defect: Player can't cannot play any improvement until [Repair] or [Intervention] remedy is played.

The first three barriers capture some of the findings from previous research on barriers to industrial energy efficiency [11] and the last two aim to reflect the potential negative consequences on product quality and environment, health and safety aspects when good practices are not systematically implemented.

3) Remedy cards (dotted background). As mentioned in the previous section, there are five types of remedies. Each remedy addresses two barriers [name in brackets]. This is to ensure that there are sufficient solutions to barriers so players would not get stuck for too long and could go through more Improvement cards.

1. Repair (and replace): Solution to [Leak, accident or product defect] and [Too high investment cost];

2. Budget (for pilot project): Solution to [Too high investment cost] and [Lack of knowledge];

3. Learning (from colleagues): Solution to [Lack of knowledge] and [Lack of communication];

4. Crisis team meeting: Solution to [Lack of communication] and [Factory closure];

5. Intervention (to bring perf. up to min. standard): Solution to [Factory closure] and [Leak, accident or product defect].

4) Immunity cards (crosshatched background). There are five unique Immunity cards in total, each based on a principle from the Lean manufacturing and addressing a specific barrier [name in brackets]:

1. Hansei \& sustainability vision: Sustainability as a mindset and core business value, making the player immune to [Too high investment cost];

2. Genshi genbutsu \& routine training: Go and see problems on-site to experience them first-hand and develop better solutions, making the player immune to [Lack of knowledge]; 
3. Yokoten \& collaborative teams: Outstanding communication within the company to enable broad dissemination of new good practices, making the player immune to [Lack of communication];

4. Kaizen \& energy champion: Performance beyond legal compliance, making the player immune to [Factory closure];

5. Muda walks \& preventive maintenance team: Outstanding shop floor layout and maintenance, making the player immune to [Leak, accident or product defect].

\section{Results}

Four pilot sessions were conduct with Airbus employees to test the game and get feedback on the usability and usefulness of the game. The four different focus groups were selected to capture a broad range of opinions on the game effectiveness and ideas on how this could be deployed at Airbus. This section describes each focus groups, the sessions' setting and the feedback provided by participants.

\subsection{The four focus groups}

Trade Union Safety Representatives (TUSR). The first pilot involved five senior safety representatives (four playing, one observing). TUSR work closely with the shop floor and were able to provide practical feedback on various elements of the game. The pilot session took place in their office which is on the shop floor, thus in the actual manufacturing environment simulated in the game. Being so close to the real-world environment provided the ideal conditions to get the "blue collar" insight into the game.

The session started with a very high level of engagement and competition between the representatives - even to the extent that they joked about putting a financial stake on the table. The focus was very much on winning with most attention given to the practices with the highest savings, and often the practices with lower savings being overlooked or trivialised. The language used on the cards was sometimes considered too technical, requiring explanation by the facilitators, which reinforced the focus on the value on the card rather than the practice itself.

The feedback from the representatives was that the game itself seemed complex to begin with but that it was easy to pick up. They thought this could be a problem with introducing it more widely to the shop floor workers. The game lasted 30 minutes which would mean it would be difficult to introduce either during normal working time or during breaks, which are short.

However they proposed a targeted approach, perhaps to other representatives first who could then cascade it to others or via a specific training session. The practices on the cards were seen as broadly relevant and the representatives were pleased to see examples of practices that they had already implemented or that they could implement in their production area. They also recognised the barriers and were pleased with the ratio of barriers to practices which made the game more free-flowing. 
Facility Management. The composition of the group for the second pilot session was quite varied and included people working on a variety of infrastructure projects and with some, but limited experience, of energy efficiency from a buildings perspective (as opposed to a manufacturing perspective as primarily addressed in the game). Two of the participants in this group already played the game before in a previous meeting in preparation for this pilot session. This function in the company is the ideal customer for the game so the feedback from this session is the most important. Despite some initial scepticism, the session was carried out successfully with good results in terms of engagement and quality of discussions after the game.

As the function responsible for energy consumption, Facility Management staff played the game with some ideas in mind about how they would like to deploy it. During the game, they considered how it could be played during the energy awareness campaigns. Although the game was shorter than the first pilot session (20 minutes), they had concerns that this would still be too long to engage with employees.

They also made the same observation as the TUSR that it was difficult to begin with but very enjoyable once the game was underway. Some of the people who played had no experience of energy efficiency and found the language difficult, but the other players with experience were able to explain.

Also as above, it was noted that it was easier to focus on the value rather than the practice. One member of staff suggested that a way of overcoming this could be to use the cards in a different way as a "higher-or-lower" style game, where the practice on the card is read out and players have to determine if the savings are higher or lower. This could also be suitable for a small number of players (perhaps only two) and a larger number of observers, which would work well with the person-at-a-stand approach for the awareness campaigns.

Manufacturing Engineering. This third pilot session was conducted with engineers who had good technical knowledge and some grasp of energy efficiency. It also was the biggest session with six players and took 45 minutes to complete. The group experience was ranging from engineering apprentices to people who have worked for Airbus for many years. Their primary interest laid in how they can build energy efficiency into their specifications for new equipment/machines rather than continuous improvement activities.

The game was picked up quickly but the level of engagement seemed lower than the other sessions. The main feedback from the engineers was that they wanted it to be highly relevant to their work and would appreciate it more if the practices were based on specific projects with specific savings figures. This would also help with understanding the practices more - and how they could be applied. One engineer suggested that a good understanding of the practices in the deck could be a useful aid for writing a specification for new manufacturing equipment and that the deck could be used a reference source. 
Environment Health \& Safety (EHS). The final session was with the EHS team. The shop floor workers invited to this session did not join as there was no interest in the session due to skepticism and limited willingness to engage. The EHS shop floor staff are mainly responsible for health and safety, with environment added as an extra responsibility but often overlooked. However, the "white collar" EHS staff were also invited and were more engaged, one of whom had played the game before. This session was the shortest at only 15 minutes in length - but even this was considered too long for using with shop floor workers.

Most of the comments from this team were related to how it could be deployed and the constraints associated with delivering it as a piece of training, either standalone or as part of another course. The team also commented on what the expected outcomes could be; gaining an awareness of good practices, barriers and their remedies is good, but this should lead to actions which allow the practices to be implemented.

\subsection{Summary of Feedback on Format and Content}

The four pilot sessions ran for a reasonably short time with the game time itself ranging from 15 to 45 minutes. There were only few issues with learning the rules and game mechanics. Most players learnt quickly and helped other players, reducing the need for external facilitation. This ensures that the game can be further deployed as experienced players can easily teach others and scale up the use of the game.

The practices on the Improvement cards, despite being considered too technical at times, was mostly relevant for the companies. A few practices were not relevant due to specificities of the production facilities at Airbus. For instance, the site does not use steam and thus all practices connected to energy savings in steam networks were not applicable. Some suggestions were made to customize the game to Airbus and include actual examples of past projects. The format in which this could be achieved was shortly discussed as including actual value of the energy savings and a full description of the practice on the cards would make it less user-friendly. Instead a reference or code could be added on the card to link to external resources and provide more complete information which could be consulted outside the game.

The Barrier and Remedy cards were also considered as relevant and sometimes added a comical element to the game. Some players invented stories explaining why their opponents would face a specific barrier or how they can solve this challenge. It is hypothesized that this type of emotional engagement with the content can enrich the learning experience and make it more memorable. Therefore, it has been suggested in subsequent games to engage with the card content through storytelling.

Finally, the Immunity cards may be considered as the most technical ones (terminology from Lean and Toyota Production System). However there was little discussion on their meaning and applicability at Airbus. This could be addressed by highlighting the importance of these cards as they are very powerful, like the "joker" or wild card in a regular playing card game. A short dictionary of the terminology used in the eco-efficiency card game could be included in the rulebook in order to give the opportunity for players to further explore Lean principles and concepts after the game. 


\section{Conclusions}

Overall, the format worked well for all focus groups. Participants quickly understood the purpose of the session (learn about eco-efficiency and get examples of practices) and the objective of the game (score 1,000 kWh of energy savings). Despite some initial difficulties to learn the rules and game mechanics, all players succeeded in playing without additional guidance, typically after one full round.

The main intended learning outcomes are to learn about: (1) sustainable manufacturing practices; (2) typical barriers to improvement; (3) remedies to these barriers; (4) systematic ways to overcome barriers based on Lean principles. The team dynamic and storytelling are instrumental to enrich the learning experience through deeper discussions on specific practices, barriers, remedies and immunities. It shows potential for the game to be a platform for knowledge exchange. Additional objectives were to increase the acceptance of serious games as educational tools; to promote experiential learning on practical topics; to enable team building and engagement with the topic of sustainability; and to encourage the recognition that eco-efficiency is feasible and actionable.

Further work is currently underway to test the card game in university lectures. So far, the card game was used for team building during the induction week of MPhil students in Industrial Systems, Manufacture and Management, and in modules on Industrial Sustainability, Sustainable Manufacturing and Energy Technologies with underand postgraduate engineering students. Early findings reveal polarized reactions amongst students with a majority of the responses strongly positive trend on gaming as a mean to learn about eco-efficiency.

\section{References}

1. Case, J.M., Light, G., 2011. Emerging methodologies in engineering education research. Journal of Engineering Education 100 (1), pp. 186-210.

2. Tilbury and Wortman, 2004. Engaging People in Sustainability. Commission on Education and Communication.

3. Scherer, Palazzo and Seidel, 2013. Managing Legitimacy in Complex and Heterogeneous Environments: Sustainable Development in a Globalised World. Journal of Management Studies 50:259-284.

4. Smith, W. and Lewis, M., 2011. Toward a Theory of Paradox: a Dynamic Equilibrium Model of Organizing. Academy of Management Review, 36(2), pp. 381-403.

5. Beech, N., Burns, H., de Caestecker, L., MacIntosh, R., and MacLean, D., 2004. Paradox as invitation to act in problematic change situations. Human Relations, 57(10), pp. 1313-1332.

6. Despeisse, M. and Evans, S., 2015. Improving Factory Resource and Energy Efficiency: the FREE Toolkit. In: Umeda, S., et al. (Eds.), Advances in Production Management Systems, IFIP Advances in Information and Communication Technology Volume 460, pp. 640-646.

7. Industrial Assessment Centers Database. https://iac.university

8. UNEP. Resource Efficient \& Cleaner Production (RECP). http://www.unep.fr/scp/cp

9. Carbon Trust. Tools, guides \& reports. http://www.carbontrust.com/resources/guides

10. The Compressed Air Challenge. Library. https://www.compressedairchallenge.org/library/

11. Lunt, P., Ball, P., and Levers, A., 2014. Barriers to industrial energy efficiency. International Journal of Energy Sector Management 8(3), pp.380-394. 